\title{
THE IMPAIRMENT OF GASTRODUODENAL MUCOSAL BARRIER BY COFFEE
}

\author{
Lubica Cibičková, Norbert Cibiček, Petr Žd'ánskýr, Pavel Kohout ${ }^{2}$ \\ students of Charles University in Prague, Faculty of Medicine in Hradec Králové, Czech Republic; University Hospital in \\ Hradec Králové: Department of Gerontology and Metabolism¹; Thomayer's University Hospital: Department of Internal \\ Median $^{2}$
}

Summary: Background: Even though coffee is not considered to be responsible for development of peptic ulcer, it may, however, prolong its healing by increasing acidity of gastric content. In our former work we observed a profound increase in sucrose permeability (above normal values) in healthy volunteers regularly drinking coffee for years. In literature, many factors affecting sucrose permeability have been described so far. None of them, however, studied the effect of coffee. Subjects, materials and methods: 10 young asymptomatic habitual coffee drinkers were included in the study. The probands underwent SaLM test twice - first time without coffee restriction and second time after 48-hour coffee abstinence. The ingested SaLM solution comprised sucrose $(25.0 \mathrm{~g})$, lactulose $(10.0 \mathrm{~g})$, mannitol $(2.0 \mathrm{~g})$, xylose $(2.0 \mathrm{~g})$ and water (up to $100 \mathrm{ml}$ ). Urine was collected for five hours and the samples were analysed using gas chromatography. Results were compared with those of 8 young healthy volunteers not drinking coffee. Permeability for sucrose was significantly higher in the group of habitual coffee drinkers in comparison with non-coffee drinkers $(p<0.01)$. After 48-hour coffee abstinence sucrose excretion decreased significantly $(p<0.05)$ to a level not differing from that of non-coffee drinkers $(p=0.54)$. Conclusions: Our results indicate that coffee may damage gastroduodenal mucosa in habitual coffee drinkers. In a time period of 48 hours the gastroduodenal mucosa is capable of a significant regeneration.

Key words: Gastrointestinal permeability, Sucrose, Coffee

\section{Introduction}

Even though coffee is not considered to be responsible for development of peptic ulcer, it may prolong its healing by increasing acidity of gastric contents (4). Coffee stimulates gastrin release and gastric acid secretion. However, no association between coffee and dyspepsia has been found. On the other hand, the most frequently reported symptom after coffee drinking is heartburn, which is in accordance with the finding that coffee promotes gastro-oesophageal reflux (1).

Sucrose permeability is established non-invasive means for evaluation of upper gastrointestinal tract impairment (13). In our former work (3) we observed a profound increase in sucrose permeability (above normal values) in healthy volunteers regularly drinking coffee for longer time.

Factors described in literature which have an effect on sucrose permeability include life-style factors (e.g. cigarette smoking (6)), drugs (e.g. NSAIDs (12) and corticosteroids (9)) and bacteria (e.g. Lactobacillus (7), Helicobacter (2)). Effects of coffee on functional integrity of upper gastrointestinal tract barrier have not been studied yet.

\section{Subjects, materials and methods}

10 young asymptomatic habitual coffee drinkers ( 2 males and 8 females, age $22.7 \pm 1.1$, range 21-24), students of medicine, were included in the study. Each individual drank minimum 1 cup of coffee ( 0.25 litre) daily for at least 1 year ( 2.2 cups, range $1-4$, for 4.3 years, range $1-8$ ). All provided written, informed consent. Since this study was methodically similar to our previous studies, which gained approval of the Ethics Committee, in this case it was not asked to approve the protocol. Subjects who smoked cigarettes, had antecedents of gastroduodenal diseases and history of NSAIDs (within last 10 years) were not included.

The habitual coffee drinkers underwent SaLM test twice - first time without coffee restriction and second time after 48-hour coffee abstinence. After night fasting the probands provided a urine sample from the second morning urine, since the first morning urine might contain adulterants capable of interferring with disaccharides during laboratory investigations. This urine was considered a control sample. After that the probands ingested SaLM solution of composition as follows: sucrose $(25.0 \mathrm{~g})$, lactulose (10.0 g), man- 
nitol (2.0 g), xylose (2.0 g) and water (up to $100 \mathrm{ml})$. After the ingestion, they fasted for 2 hours without intake of fluids. During the next three hours the probands excluded meals and drinks containing sugar. In this 5-hour period, urine was collected into a container (two drops of $1 \%$ thiomersal were added as a conservant). Samples of this urine were compared with control samples and were analysed using gas chromatography. The samples were either processed immediately after delivery, or were kept frozen at $-20^{\circ} \mathrm{C}$. After centrifugation, $50 \mu \mathrm{l}$ with addition of internal standard (sorbose) and reference material (inositol) were evaporated to dryness under nitrogen. The residue was derivatised using hydroxylamine hydrochloride to produce oximes, which were then sylilated with N,O-bis-(trimethylsilyl)-trifluoracetamide (BSTFA) to produce trimethylsilylethers. These products were determined using capillary gas chromatograph (Hewlett-Packard 5890 II, series II with a flame ionisation detector and integrator HP 3396A, capillary column HP-5). The obtained data were analysed using CSW 32 software (Data Apex).

The results were compared with 8 young healthy nonsmokers not drinking coffee ( 5 males and 3 females, age $22.1 \pm 1.8$, range 19-25). This group was considered a control group. They underwent the SaLM test once as described above.

\section{Results}

The mean sucrose permeability in the control group was $0.059 \% \pm 0.025$ as opposed to habitual coffee drinkers without coffee restriction with mean sucrose permeability equal to $0.203 \% \pm 0.112$ (see Fig. 1). The sucrose permeability was significantly higher in the latter group in comparison with the former group $(\mathrm{p}<0.01$, two-sample test).

In habitual coffee drinkers after 48-hour coffee abstinence, sucrose excretion decreased significantly $(\mathrm{p}<0.05$, paired T-Test) to $0.107 \% \pm 0.088$. The reached level of sucrose permeability was not differing from that of noncoffee drinkers ( $p=0.54$, Kolmogorov-Smirov test).

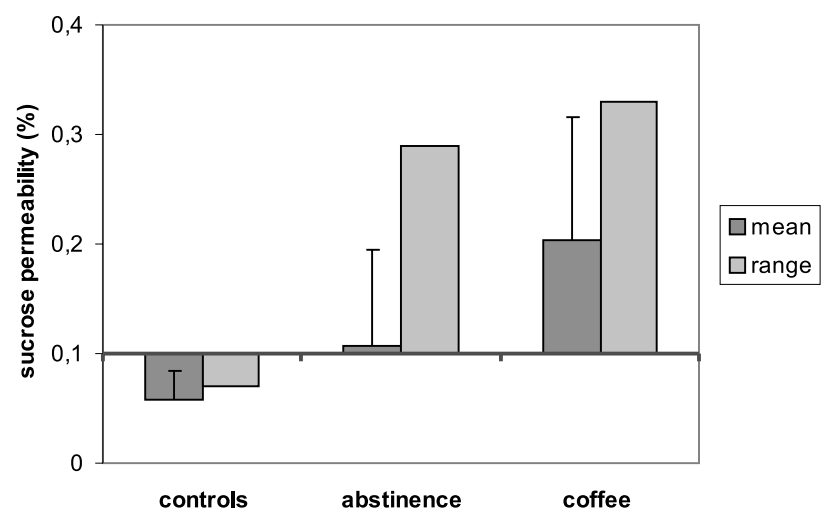

Fig. 1: Permeability for sucrose in unrestricted coffee drinkers and after abstinence.

\section{Discussion}

The normal value obtained from healthy probands not drinking coffee by adding two standard deviations to mean (less than $0.11 \%$ ) supports the value found by ROC (Receiver operating characteristic) analysis (less than $0.10 \%$ with $95 \%$ sensitivity and $33 \%$ specificity) using volunteers with no respect to habitual coffee drinking (3).

We are aware of some limitations as to the interpretation of our results. Firstly, and not surprisingly, we found standard deviation and range of sucrose permeabilities to be substantially high, especially in the group of coffee drinkers. This finding is consistent with permeability tests in general, and makes them problematic with respect to recommendations for clinical utilisation. This variability may, to some extent, be explained on one hand by known and described factors (starting with complete ingestion of testing solution and ending up with accuracy of laboratory analysis) and on the other hand by differences in quantity and quality of mucosal damage, as seen in the trends of standard deviation. However, the range indicates (in compliance with the concrete values), that the value of sucrose permeability depends quite considerably on an individual, even though the importance and in our case also significance of the mean is indisputable (see Fig. 1). As for clinical praxis, in the light of these conclusions further specifications ought to be included into sucrose permeability protocols (not excluding the use of alcoholic beverages, cigarette smoking etc.).

Secondly, neither of our groups of volunteers was examined endoscopically. Therefore, an asymptomatic organic damage to the upper gastrointestinal tract mucosa could not be excluded. Nevertheless, with regard to healthy probands, we do not intend to minimalize this limitation (in order to keep the convenience of the study).

Thirdly, some authors have shown that the gastroduodenal mucosal barrier is altered by Helicobacter pylori infection $(2,5,14)$. Other studies, however, did not support this finding $(8,11,15)$. Bearing this controversy in mind, we cannot tell for sure that our groups of probands are comparable. Therefore, we find it beneficial to include a non-invasive Helicobacter pylori test (e.g. a breath test) in future.

Fourthly, some authors suggest, that caffeine might slow gastric emptying (1). It might hence increase the exposure of gastric mucosa to sucrose. Be that the case, it would be for us problematic to determine the extent of its damaging effect in this area, since transit time also affects the results of permeability tests in general. In our study, it could therefore possibly be co-responsible for the increase of sucrose in urine. Since other studies $(1,10)$ indicate that coffee does not affect gastric emptying or small bowel transit, we considered this questionable effect of caffeine negligible. Lastly, our study uses a small group of volunteers. To obtain solid results for clinical praxis a much larger group ought to be studied. 


\section{Conclusions}

Our results indicate that coffee may damage gastroduodenal mucosa in habitual coffee drinkers. In a time period of 48 hours the gastroduodenal mucosa is capable of a significant regeneration.

Hence, our findings will modify the protocols for sucrose permeability tests. The patients undergoing these tests should not drink coffee at least for 2 days before the test. Otherwise habitual coffee drinking ought to be taken into consideration and the results should be interpreted adequately.

\section{Acknowledgements}

The authors would like to thank the working team of the Laboratory of the Department of Gerontology and Metabolism, University Hospital in Hradec Králové, Czech Republic, and RNDr. E. Čermáková for her kind help with statistics.

\section{References}

1. Boekema PJ, Samsom M, van Berge Henegouwen GP, Smout AJ. Coffee an gastrointestinal function: facts and fiction. A review. Scand J Gastroenterol Suppl 1999;230:35-9.

2. Borch K, Sjostedt C, Hannenstad U, Soderholm JD, Franzen L, Mardh S. Asymptomatic Helicobacter pylori gastritis is associated with increased sucrose permeability. Dig Dis Sci 1998;43:749-53.

3. Cibiček N, Cibičková L, Kohout P, Ždánský P. Využití testu propustnosti pro sacharózu (SaLM) v detekci postižení sliznic horní části trávicí trubice u pacientú s horním dyspeptickým syndromem - pilotní studie. Acta Medica (Hradec Králové) Suppl 2004;47(1):23-28

4. Fixa B. Peptický vřed In: Bureš J et al. Základy vnitřniho lékařství, Praha: Galén 2003:280.
5. Fukuda Y., Bamba H., Okui $\mathrm{M}$ et al. Helicobacter pylori infection increases mucosal permeability of the stomach and intestine. Digestion 2001;63 (Supp 1):93-96.

6. Gotteland M, Cruchet S, Frau V et al. Effect of acute cigarette smoking, alone or with alcohol, on gastric barrier function in healthy volunteers. Dig Liver Dis 2002; 34(10):702-6.

7. Gotteland M, Cruchet S, Verbeke S. Effect of Lactobacillus ingestion on the gastrointestinal mucosal barrier alterations induced by indometacin in humans. Aliment Pharmacol Ther 2001;15:11-7.

8. Graham DY. Pathogenesis of increased sucrose permeability in H. pylori gastritis. Dig Dis Sci 2000;45:889.

9. Kisiltas S, Imeryuz N, Gurcan T et al. Corticosteroid therapy augments gastroduodenal permeability to sucrose. Am Coll of Gastroenterology 1998;93: 2420-4.

10. Nieuwenhoven MA, Brummer RJM, Brouns F. Gastrointestinal function during exercise: comparison of water, sports drink, and sports drink with caffeine. J Appl Physiol 2000;89:1079-85.

11. Rabassa AA, Goodgame R, Sutton FM, Ou CN, Rogenerud C, Graham DY. Effects of aspirin and Helicobacter pylori on the gastroduodenal mucosal permeability to sucrose. Gut 1996;39:159-63.

12. Smecuol E, Bai JC, Vazques H. Acute gastrointestinal permeability responses to different non-steroidal anti-inflammatory drugs. Gut 2001;49(5):650-5.

13. Sutherland LR, Verhoef M, Wallace JL, Van Rosendaal G, Crutcher R, Meddings JB. A simple, non-invasive marker of gastric damage: sucrose permeability. Lancet 1994;343:998-1000.

14. Suzuki K, Yasuo K, Sawada N et al. SS1 Helicobacter pylori disrupts the paracellular barrier of the gastric mucosa and leads to neutrophilic gastritis in mice. Virchows Arch 2002;440:318-24.

15. Vera JF, Gotteland M, Chavez E, Vial MT, Kakariek E, Brunser O. Sucrose Permeability in children with gastric damage and Helicobacter pylori infection. J Pediatr Gastroenterol Nutr 1997:24:506-11.

Submitted April 2004

Accepted September 2004.

Lubica Cibičková,

Velká 156, 75301 Hranice,

Czech Republic.

e-mail: cibickova@seznam.cz 